\title{
Loving Help from the Other Side: A Mosaic of Some Near-Death, and Near-Death-Like, Experiences
}

\author{
William J. Serdahely, Ph.D. \\ Montana State University
}

ABSTRACT: Persons who have Stage 5 or Transcendental near-death experiences frequently report they were given a message that they should be more loving and helpful to others upon returning to their bodies. On the other hand, some persons who have had near-death, or near-death-like, experiences report receiving loving help from "the other side." I propose that these reports are evidence that the other side "practices what it preaches."

In Heading Toward Omega, Kenneth Ring (1984) proposed his thesis that the transformations seen in near-death experiences are harbingers of a change in the consciousness of the human species. Based on a study of his 111 most robust "near-deathers," Ring suggested the future will be characterized by a more loving, harmonious way of being, as humanity moves towards Omega, or the end point of human evolution.

Having contacted or been contacted by 154 respondents at the time of this writing (of whom 126 are primary sources), I believe another thesis, or mosaic if you will, can be constructed from near-death, and near-death-like, experience data. As I was fitting together the "tiles" of this mosaic, a picture came into focus suggesting that some near-death, and near-death-like, experiencers receive loving help from the other side.

William J. Serdahely, Ph.D., is Professor of Health Science at Montana State University. Reprint requests should be addressed to Dr. Serdahely at the Department of Health and Human Development, Montana State University, Bozeman, MT 59717. 
The messages of "love" and "helping" are not new to those familiar with the near-death experience (NDE). It is not uncommon to hear Stage 5 (Ring, 1980) or Transcendental (Greyson, 1983) NDErs say that while they were in the Light, or in contact with the "Being of Light," to use Raymond Moody's phrase (Moody and Perry, 1988), they were given two primary messages: (1) to be a loving person, showing more compassion, acceptance, and tolerance for others; and (2) to be a helping person, giving selflessly to others (Sutherland, 1991).

One of my respondents, who was 37 at the time of her Stage 5/Transcendental NDE, was "told" the following by the Light:

This is your life, your chance.

Do something good for the world.

Love everything and everyone.

Be a peaceful person.

Here again, we see the messages of helping ("Do something good for the world") and of love ("Love everything and everyone") imparted to an NDEr by the Light.

However, while a number of NDErs have been told to be more loving and helping, others have in addition been the recipients of loving help from the other side. It is this latter thesis that I develop in the remainder of this paper.

I have called this a "mosaic" for several reasons. First, it is constructed not only from near-death experiences but also from neardeath-like experiences: out-of-body experiences independent of NDEs, comas, dreams, visions, apparitions, and deathbed or predeath visions. Second, not unlike mosaic fragments discovered by an archeologist, my "mosaic," too, is incomplete; some of the "tiles" are missing, but enough are now in place to see a pattern, albeit an incomplete one. Third, this mosaic is pieced together from a nonrandom sample, which, of course, may give us a distorted view, perhaps not unlike a fresco pushed out from an ancient wall that is no longer "in square." Fourth, while enough tiles are now in place to put forth the thesis of "loving help from the other side," I know as a researcher that more information could have been elicited from some of my respondents who, because of the exigency of time or the element of trust, only revealed just so much. I also know I would have liked to have received "tiles" from prospective respondents who never agreed to an interview; our mosaic would then have been even more detailed. Given the realities of doing this kind of research, I am painfully aware that my mosaic is incomplete. 
Even so, our trowels have scraped away enough dirt and our brushes have swept away enough dust, and we have stepped back far enough from the fresco so that we can now see a beautiful, multicolored pattern of loving help from the other side emerge, perhaps well exemplified by the following two interconnected experiences:

Wendy (a pseudonym) is now 4 years old. When she was 3 , she was dying from hydrocephalus. She had to have major brain surgery, from which she made a remarkable recovery, according to her mother. Wendy later told her grandmother, "See, I told you Jesus said He would heal my head." She had had an apparition of Jesus prior to the surgery.

Wendy's experience was related to me by her mother. The night before the surgery, her mother was quite distressed and distraught. She, too, saw an apparition of Jesus, who said, "Call my name, and I'll be there for you." Wendy's mother said Jesus, surrounded in white light, stayed with her the whole night long. The next day Wendy's surgery went just fine: loving help from the other side.

\section{Adult NDEs}

A total of 80 NDEs have been related to me by 66 persons, some of whom had multiple near-death experiences. Fifty-six respondents were primary sources; 8 were secondary sources; and 2 were both.

Throughout this paper, unless otherwise specified, I will describe only the experiences of primary sources, drawing on those cases where loving help was received from the other side. It should be noted, however, that these comprise a minority of the cases. From the accounts I have collected, clearly not everyone was a recipient. In describing these cases, I use pseudonyms as above to protect my respondents' privacy and honor their desire for confidentiality.

At least 10 of my NDErs who had near-death experiences as adults received loving help from the other side. I will present a brief description of each case in an effort to piece together the tiles of this mosaic.

David at 35 or 36 years of age had his second NDE. At one point during his near-death experience, he encountered his deceased grandmother, to whom he had been very close when she was alive, smiling, her hands extended, welcoming him to a beautiful meadow. David said his grandmother is "a guardian angel for me."

Susan, at 33, and Donald, who was about 37, each encountered a group of friendly, kind, and smiling spirits during their respective 
NDEs. Susan and Donald independently said these spirits were there "rooting" for them and for their well-being. Susan said she was totally loved by these spirits, who were sent for her benefit. They "told" her she would be fine. Donald said his group of spirits was "happy" to see him.

Kathy, the 37-year-old NDEr whose message from the Light I cited above, noticed a "figure" at the end of the operating table during the out-of-body phase of her NDE. While out of her body, Kathy was able to identify the various medical providers working on her, but not this "figure." Later, she came to believe this figure was her "guardian angel."

Rose nearly died due to an overdose of anesthetic administered by her dentist. She then experienced "a white figure" who came and stood beside her while she was in the dental chair. She said, "He took my hand."

Carol had an NDE at 38 during a difficult delivery in which her uterus ruptured. Moving into a very bright, warm light, she asked, "Am I dying?" A voice responded, "No, I will not let you die." At this point, she knew she was going to be fine and felt very protected. Shortly thereafter, she had a second NDE in which Jesus or God lifted her up and held her. She felt blanketed with love and safety. Her doctors later said they hadn't expected her to live and that she had looked like "a gray lump" during her second close-to-death encounter.

Joan tried to kill herself when she was 27 . She recalled screaming as she went into her NDE, "God, please let me know You forgive me before I die." From a bright light came two big hands, and then a loving, gentle voice, which took away all of Joan's fear, said, "Lift up your hands. I forgive you. I forgive you. I'll give you a second chance." Joan said God was love, compassion, kindness, total acceptance, and joy, and that He had a sense of humor and made her laugh. At one point during her NDE, she said, "I was silly, Lord," and He laughed. When she held His hands, her pain left her.

Gina told me about her "quick recovery" from peritonitis, which had set in after a therapeutic abortion when she was 28 . A "beautiful, beautiful golden white light" engulfed her during her NDE. She then felt "loved, warm, loving, and forgiven for the abortion." She went home from the hospital a few days later, having quickly recovered from the peritonitis.

During her second NDE, Ann, who was 20 at the time, was also encapsulated in a bright light. She had collapsed from acute hemorrhagic pancreatitis and wasn't expected by her doctors to live. But she went home within a week of her NDE. She said her doctor had never 
seen such rapid healing; he was astounded, given how very ill she had been.

At 30, Gary reported, he had been suffering from high blood pressure, uremic poisoning, fluid in both lungs, cardiac tamponade, and endocarditis. While on hemodialysis, he saw his "retinas explode into the vitreous." He then collapsed, calling out, "Help me; please help me." From there, he went into an NDE in which, he said, "Now I could see everything." He encountered a white-yellow light that he knew was God. Three days after his NDE, he had a vision in which he begged God to take him back to "heaven" where he had felt "absolute unconditional feelings of love." A voice said, "Gary, you have more work to do." He then saw two gigantic cupped hands, and he placed himself in those two hands and said, "OK, let's go." On the fourth day, he was assessed by his physicians, who were awed by his improved state of health. He reported, "The fluids were gone [from my lungs], the [pericardial] sac was OK, my blood pressure was down. My heart murmur was gone." Because of his encounter with God, Gary does not consider his blindness a disability. At age 46 , he believes he is now able to "see into one's soul" as a result of his NDE.

\section{Retrospective Childhood NDEs}

I have collected 28 accounts of childhood NDEs related by 26 adults reporting retrospectively about their NDEs as minors. Twenty-five of these adults are primary sources. At least 2 of these respondents were recipients of loving help from the other side in their childhood NDEs.

When Eric was 5 , he fell into the murky water between a barge and a tug boat. He said he did not know how to swim. Suddenly, a "shaft" (his word) of white light covered his body vertically, and a reassuring, calming, encouraging male voice said, "Climb up the stairs; climb up the stairs." Eric said, "It was as though [the shaft of white light] was there for me to climb." The light extended to the water's surface. Eric went on to say that as a child he had never climbed a ladder, so the message to climb stairs made sense to him.

Penny (about whom I have written elsewhere) had an NDE sometime between the ages of 10 and 12 (Serdahely, 1987-88). Her NDE was precipitated by the sexual and physical abuse perpetrated by her father to the point she thought she might well die from his actions. As Penny's NDE unfolded, she found herself being held and embraced by a "beautiful lady" with a gentle, compassionate voice. In Penny's mind, this graceful, gentle female spirit was clearly there to provide comfort 
and support for her and that this female spirit would be there for any suffering or "helpless" (Penny's word) child: loving help from the other side.

\section{Contemporary Pediatric NDEs}

I have collected 12 pediatric NDEs where the young person described his or her near-death experience while still a minor. Five of these cases came from primary sources, and 7 were from secondary sources. I have at least 4 examples of the "loving help" mosaic from this group. I will briefly describe 3 pediatric NDEs, all of which are from primary sources.

When Pat was 7, during his NDE he was met in a dark tunnel by his two deceased pets (Serdahely, 1989-90). No other loved ones close to him had died at the time of his close-to-death encounter. His deceased pets seemed to reassure and comfort him by being there with him, licking his hand, and being petted by him. They also sent him back to his body, after his dog licked Pat's face.

Amber, at age 10, was recovering from spinal surgery in an intensive care unit when her heart and breathing stopped. She was clinically dead for approximately 30 seconds. During her NDE, she found herself "in a dark place" where a "gentle," "loving" white lamb appeared to her. The lamb came close to her and then ran away, after which she regained consciousness. As with Pat, the previous pediatric NDEr, Amber also had no loved ones close to her who were deceased; however, she is "an animal lover" (Serdahely, 1990a). It appears that for both Pat and Amber loving help came to them in the form of animal spirits.

Mike, having fallen from a high diving board onto the concrete below when he was 4, found himself surrounded by a shaft of bright, warm, yellow light. He felt a warm hand on his shoulder, and a comforting, loving male voice gave him the choice of staying or going back (Serdahely, 1990b). Mike said he didn't turn around to see who was "speaking" to him, but he said the male was like his friend who wouldn't hurt him. Mike said the male may have been Jesus.

\section{Out-of-Body Experiences (OBEs)}

Twelve people, all primary sources, reported OBEs not associated with NDEs, clinical death, or dreams. Some of these respondents had multiple OBEs over a period of time, precipitated by meditation, by getting hurt or being in pain, or by trances. 
When Lois was about 23 , she went into a trance and found herself in "an all-light filled space" with an even brighter light in the center. Feeling "total peace, total love, and a contentment so great I felt relief," she then encountered a "light-being," her "long-lost friend" and mentor, Jane, who had died 9 years previously. Jane said, "Isn't it beautiful here?" over and over again. Later, Lois wrote to me saying that her OBE and encounter with Jane "instilled a knowledge of life everlasting and at the same time caused me to become a diligent searcher of greater knowing." Lois went on to say she was "extremely attached" to Jane. At the very time Jane died from being electrocuted, Lois was some 150 miles away; she wrote, "[I was] thrown to the ground in agony and felt as if I was being jolted out of myself."

Rhoda, at about age 3 , found herself being sexually molested and physically abused by an uncle, with nowhere to go and no one to come to her aid. Her mother was in the hospital about to deliver a baby, accompanied by her father. While not having an NDE per se, as she wasn't nearly killed in this instance, she suddenly found herself out of her body. As she moved into a darkness, a comforting but firm voice told her she must go back. She did go back but not all the way back to her body. Rhoda remained floating in the darkness. Then a bright intense white and yellow light of total comfort surrounded her, and Mary appeared. Mary told Rhoda in a motherly, loving way that she had to go back, but that Mary would be with her; she wouldn't be alone. Mary reached out with Her hands taking Rhoda by her right hand. Mary embraced Rhoda, and she was immediately back in her body. Then a beam of that same bright light shone down, blinding Rhoda and preventing her from seeing the abuse being perpetrated on her: loving help from the other side.

\section{Dreams}

I have collected 48 dreams from 28 people, 18 of whom are primary sources, 7 secondary sources, and 3 both. These dreams have deathrelated content to them, and a number sound very similar to NDEs or sound as if the experiencers were having OBEs during the sleep state.

John was about 28 at the time of a diagnosis of a terminal brain cancer; his medical providers gave him about 3 months to live. He lived for 18 months after the diagnosis. I heard about his dream from his wife before he died and told her I thought John would die soon after that dream; he died about $1 \frac{112}{2}$ weeks later.

John dreamed he went to a place with a white hedge. On the other side of the hedge were many people with friendly faces, reminiscent of 
Susan and Donald above who encountered a group of friendly spirits "rooting" for them. One of these people was John's deceased cousin, who waved and nodded her head to beckon him to come across. John's wife wrote to me saying, "When [John] woke up he was very excited about his dream and from that point on, seemed to almost look forward to dying." I suggest he was a recipient of loving help from the other side, which allowed this man, who held on for so long, to pass over peacefully.

Lauren wrote to me saying, "As a result of the emotional battering [from her parents and teachers] I often wondered if I was loved, or even wanted. At approximately [age 10], the question of 'Am I loved by anyone?' became very intense with me. One night I had a 'dream.'" (Lauren put the word "dream" in quotation marks in her letter.) In her "dream," she had gone through a very dark door into a beautiful place with "perfect" flowers and grass and "perfect" colors. There was a clear, beautiful stream and an "unexplainable perfect blue" sky. Jesus took her hand, and they walked to a bridge of "perfect" white color, which spanned the stream. This place was infused with a warm, loving light "like the sun; however there was no sun as we know it." At this point, Lauren felt a very intense love. "I knew then that someone loved and truly cared for me." At the crest of the bridge, Jesus said, "No, you must go back now. It's not your time to be here yet." As Lauren started to cross that "perfect" lawn to go back, everything went black, and she woke up from the dream. When Lauren told her parents about the "dream" and that she believed it really happened to her, her parents told her to "stop imagining such things." Readers may be struck with the remarkable similarity of Lauren's "dream" to an NDE. I believe she had an out-of-body experience during the sleep state.

A number of other people have told me about their dreams that, I suggest, provided them with loving help from the other side. I will briefly summarize some of these dreams here.

Sarah's recently deceased father came to her in a dream to tell her he loved her before he had to go "to another place." Jill's recently deceased husband came to her in a dream to say that he was fine and that she and the three children would be fine, too.

Jeremy's 7 year old son, upon awakening one morning, already knew his grandmother had died that previous night before being told by his parents. The boy had a dream of his grandmother who had smiled at him, perhaps her way of saying "goodbye" to her grandson.

Stuart, suffering from quadriplegia from birth and confined to a severely contracted body, reported having several dreams in which he floated out of his body and over the city in which he resides, to be embraced and held by Jesus (Serdahely and Walker, 1990b). 


\section{Visions}

Seven visions were related to me by 7 people. Four were primary sources, and 3 were secondary sources. For the purposes of this paper, I define a vision as a scene witnessed or perceived while awake. While visions are very similar to apparitions, the 7 visions in my files had more content to them than only seeing a spirit or person, which I differentiate as an apparition. These 7 visions are further differentiated from deathbed visions, or predeath visions, in that the former were perceived by people who were not dying or terminally ill.

Doug's vision is a good example of receiving loving help from the other side. At 22, he was devastated by the suicide of his father, whom he loved very much. Doug was distraught for months following his father's death. He met with me on a weekly basis, often sharing his confusion and his anger about the suicide. Then one day he told me about a recent vision he had had. He had been making a drive he had made many times before, and became mesmerized by the repetition. Suddenly, he "felt" a tap on his shoulder and when he "turned around," he "saw" his dad, whose arms were extended to give him a hug. When Doug and I talked about his vision, I said I thought the message was that his father was still "in touch" with him even though he was dead. Doug's dreams of his father gave additional messages to the effect that Doug should get on with his life, and that his father was fine.

\section{Apparitions}

Twenty apparitions reported by 15 people are in my files. Eight of these respondents are primary sources, 6 secondary, and 1 is both a primary and a secondary source. As mentioned in the previous section, an apparition, as I define it in this paper, is similar to a vision but with an apparition the respondent perceives only a figure or figures without a scene of some sort unfolding.

Nancy, at 28 or 29 , went to the funeral of an uncle. She touched his "stone cold body" and shortly thereafter she saw an apparition of him. He said, "Don't be alarmed. It's not me. I'm just fine."

At age 11, Gloria's cousin, who died quite suddenly in an auto accident, appeared at the foot of her bed. Gloria dearly loved her older cousin and felt very close to her when she was alive, the two of them having often shared many activities. Gloria told me she thought her cousin's appearance was her way of saying "goodbye" to her, as there was no time to do so due to the unexpectedness of the accident. 
Paula perceived apparitions of 3 children by her bed one day. She had had 3 abortions over the years due to relationship problems and had become quite depressed about "killing" (her word) her children. She had spent the previous several days in bed feeling depressed and guilty about the abortions. The 3 children apparitions told her they "forgave" her for what she did. After perceiving these apparitions, her guilt was relieved, and she was freed to get on with her life.

When Anita was 18, and 7 months pregnant, her husband said that if the baby was a girl, he wouldn't bring Anita and the baby home from the hospital, a thought that was weighing heavily on Anita's mind. Then one morning at 2:00, she saw the figure of a man at the foot of her bed. She could see right through him. He gave off a white light, which filled the room. He had no reflection in a mirror positioned directly behind him. He telepathically told Anita the baby would be fine, she would have a boy, and she should not worry. (At this point in our interview, Anita cried.) The message from this male apparition brought great relief and peace to her, and then he was just gone. "It was real; it happened," she told me.

\section{Deathbed Visions}

I have collected 15 deathbed visions, or predeath visions, reported by 11 people, all of whom are secondary sources. As with the other paranormal events described above, deathbed visions may provide the experiencer with loving help from the other side.

Karen's great-grandmother was dying and was very concerned about her affairs not being in order. A female "angel" (her word) appeared to this woman telling her, "Don't worry. Everything will be fine." The next day, Karen's great-grandmother died.

Bhola's wife had been in an extended coma, and the local hospice organization had provided nurses and volunteers to assist this woman and her family, who happened to be Hindus from India. One evening surrounded by her husband, son, and daughter, this woman, who had not stirred for a week while comatose, suddenly sat up, looked at the ceiling, extended her arms, and died. It would appear that she had had a deathbed vision that helped her make the transition.

A hospice nurse recently told me about a dying older male patient for whom she was caring. He had had several visions of deceased people from his past prior to a very restless night. That morning he was very alert and wanted cornflakes for breakfast. Soon after that, he sat up and looked past his sons. His eyes became huge and "trance-like," 
according to the hospice nurse. He said, "Let's go. It's Jesus. Let's go." He died 45 minutes later.

\section{Comas}

Seven comas were reported to me by 6 people. In the coma cases referred to in this section of the paper, the coma was the central feature described, even though the coma in some instances may have been a part of an NDE. Four comas come from secondary sources, 1 from a primary source (which I will cite below), and 1 from both.

Marcia was 12 at the time her horse rolled over her. She immediately went into a coma. She was then shuttled to 7 different hospitals because "[none] of the hospitals wanted to keep me because I was in a deep coma and not expected to live." Finally, a small private hospital accepted her.

Marcia went on to write that she was in a coma for approximately 10 days. She recalled having, when she regained consciousness, a "peaceful feeling that overtook me." She developed "a profound sense of purpose" after leaving the hospital, and she no longer feared death, similar to the transformations reported by NDErs.

While Marcia never saw anyone during her coma, she did say, "I do remember feeling someone always near me and I trusted them": loving help from the other side. Marcia added that at 30, her age at the time of her writing to me, she "still feels this presence when I am feeling desperate over things I cannot control."

\section{Healing Experiences}

I have collected 15 healing experiences reported by 15 people, 10 of whom are primary sources and 5 secondary sources. I will cite one final primary source to make the case that in a variety of circumstances some people may be the recipients of loving help from the other side.

Peter was 27 when he was about to undergo a fourth operation to remove an abscess between his diaphragm and his liver. He wrote, "The abscess prohibited taking a full breath into my lungs." Prior to the operation, he said he was "laying on my back on a freezing table when I felt a warm hand on my shoulder and a voice said, 'Don't worry, everything will be OK.' At this point I felt relief and could take a full breath without pain." Peter went on to say that later he "learned that the abscess, which had been located with a CAT scan, had disappeared. 
There was no sign of infection in my lower GI area." Peter strongly believed that it was Jesus whom he heard and who touched him, and that Jesus healed him.

\section{Conclusion}

Clearly not every NDEr or person with an NDE-like experience received help from the other side; a minority of such cases emerged from my 154 respondents. However, enough "tiles" are in place that I begin to see a mosaic of loving help, whether the person had an NDE, an $\mathrm{OBE}$, a dream, a vision, an apparition, a deathbed vision, a coma, or in Peter's case above, a clairaudient experience.

Stage 5 NDErs, having had the most robust experience, say that what they learned during their NDEs was the importance of love and loving others, often phrased as unconditional love; and helping others, often said to be a mission or a purpose yet to be fulfilled. And, yet, as the above cases suggest, the other side, if you will, "practices what it preaches": loving help from the other side was given to a number of the respondents in my files, whether that came in the form of a warm hand; a gentle, comforting voice; a loving light; the appearance of an apparition; or the embrace of a spirit. A mosaic has emerged to suggest some experiencers are recipients of loving help from the other side.

\section{References}

Grey, M. (1985). Return from death: An exploration of the near-death experience. London, England: Arkana.

Greyson, B. (1983). The near-death experience scale: Construction, reliability, and validity. Journal of Nervous and Mental Disease, 171, 369-75.

Moody, R.A., and Perry, P. (1988). The light beyond. New York, NY: Bantam.

Ring, K. (1980). Life at death. A scientific investigation of the near-death experience. New York, NY: Coward, McCann and Geoghegan.

Ring, K. (1984). Heading toward Omega: In search of the meaning of the near-death experience. New York, NY: William Morrow.

Serdahely, W.J. (1987-88). The near-death experience: Is the presence always the higher self? Omega, 18, 129-34.

Serdahely, W.J. (1989-90). A pediatric near-death experience: Tunnel variants. Omega, $20,55-62$.

Serdahely, W.J. (1990a). Letter to editor. Omega, 21, 249-50.

Serdahely, W.J. (1990b). Pediatric near-death experiences. Journal of Near-Death Studies, 9, 33-39.

Serdahely, W.J., and Walker, B.A. (1990b). The near-death experience of a non-verbal person with congenital quadriplegia. Journal of Nean-Death Studies, 9, 91-96.

Sutherland, C. (1991). A very different way: A sociological investigation of life after a near-death experience. Unpublished doctoral dissertation, University of New South Wales, Kensington, Australia. 